\section{The potentiometric titratrion of aluminum and gallium with tetraphenylborate*}

Walter S. Selig

Lawrence Livermore National Laboratory, University of California, P. O. Box 808, Livermore, CA 94550, USA

\section{Potentiometrische Titration von Aluminium und Gallium mit Tetraphenylborat}

Various cations have previously been determined as their oxonium complexes by potentiometric titration vs. tetraphenylborate (TPB). This includes the alkaline earth metals [1], the rare earth elements [2], and lead [2,3]. Some of these elements can, in fact, be sequentially estimated $[1,2]$. With the exception of lead, these elements are in group IIA or IIIB of the periodic table of the elements.

We now report that aluminum and gallium, in group IIIA of the periodic table, can similarly be determined. The oxonium complexes were formed by addition of polyethylene glycol (PEG) of average molecular weight 20,000 , and were potentiometrically titrated with a $0.05 \mathrm{~mol} / \mathrm{l}$ TPB solution.

\footnotetext{
* Work performed under the auspices of the U. S. Department of Energy by the Lawrence Livermore National Laboratory under contract number W-7405-ENG-48
}

Emf's were monitored with a coated-graphite sensor and a double-junction reference electrode. The detailed experimental conditions were previously reported [2]. Note that the equivalent weights of $\mathrm{Al}$ and $\mathrm{Ga}$ in this titration are one third of the atomic weights. These elements can be estimated only over a fairly narrow $\mathrm{pH}$ range: gallium from $\mathrm{pH} 1.55$ to 1.75 , and aluminum from $\mathrm{pH} 2.3$ to 3.0 , with an optimum at $\mathrm{pH} 2.65 .1 \mathrm{mg}$ of aluminum was determined with a standard deviation of $0.003 \mathrm{mg}$ for 6 replicates; $3 \mathrm{mg}$ of gallium were determined with a standard deviation of $0.020 \mathrm{mg}$ for 7 replicates. The endpoint inflection for gallium was not as steep as for aluminum which accounts for the larger standard deviation in its recovery.

Aluminum plus gallium yielded only a single inflection for the sum of the elements; this was found also for barium plus gallium. Indium did not yield an inflection at all. This is similar to the potentiometric titration vs. cetylpyridinium chloride which was applicable only to gallium, and not to indium [4].

\section{References}

1. Selig WS (1986) Fresenius Z Anal Chem 325:616

2. Selig WS (1988) Microchem J 37:155

3. Xiang Y, Yang B, Liu M (1985) Huaxue Xuebao 43:1203; through (1986) Chem Abstr 104:179259g

4. Selig WS (1986) Microchem J 34:148

Received May 25, 1988

\section{Ion-exchange high-performance liquid chromato- graphic determination of leukotrienes after pre- column derivatisation with o-phthaldialdehyde}

\author{
Dimitrios Tsikas and Gorig Brunner \\ Division of Gastroenterology and Hepatology, \\ Medizinische Hochschule Hannover, Podbielskistrasse 380 , \\ D-3000 Hannover 51, Federal Republic of Germany
}

Ionen-Austauscher-HPLC-Bestimmung von Leukotrienen nach Vorsäulen-Derivatisierung mit o-Phthaldialdehyd

\section{Introduction}

Cysteinyl leukotrienes $\mathrm{LTC}_{\mathbf{4}}, \mathrm{LTD}_{4}$ and $\mathrm{LTE}_{\mathbf{4}}$ are endogenous mediators in anaphylactic and inflammatory reactions [1, 2]. The increasing interest in the biochemistry of the leukotrienes has necessitated the development of sensitive methods for the determination of these metabolites. Reversed-phase high-performance liquid chromatography (HPLC) with detection by UV, radioactivity and fluorescence are the most widely used chromatographic methods for the determination of leukotrienes $[3-7]$. We have developed a HPLC method for the determination of $\mathrm{LTC}_{4}, \mathrm{LTD}_{4}$, and $\mathrm{LTE}_{4}$ using an ion-exchange column and pre-column derivatization with o-phthaldialdehyde.

Offprint requests to: $\mathrm{G}$. Brunner

\section{Experimental}

Reagents and materials. Cysteinyl leukotrienes $\mathrm{LTC}_{4}, \mathrm{LTD}_{4}$, and $\mathrm{LTE}_{4}$ were purchased from Paesel (Frankfurt, FRG) and used as received. o-Phthaldialdehyde (OPA) and ammonium acetate were obtained from Fluka (Neu-Ulm, FRG). 2-Mercaptoethanol was purchased from Schuchardt (München, FRG). Methanol for HPLC and all other chemicals were from Merck (Darmstadt, FRG). All reagents were of the highest quality available and were stored as recommended. The column $(200 \mathrm{~mm}$ $\times 4.6 \mathrm{~mm}$ I.D.) packed with an ion-exchange material, $100-$ $5 \mathrm{NH}_{2}$ Nucleosil, was obtained from Macherey-Nagel (Düren, FRG).

Chromatography. The HPLC system consisted of a Model 2156 (LKB, Sweden) microprocessor-controlled HPLC pump with heads and capillaries made of titanium. Samples were loaded with a Rheodyne high-pressure sampling injection valve provided with a $200 \mu \mathrm{l}$ sample loop. Column effluent was monitored with a Model RF-530 (Shimadzu, Japan) variable wavelength fluorescent detector. The cell volume was $12 \mu \mathrm{l}$. The wavelengths were set to emission $450 \mathrm{~nm}$ and to excitation $338 \mathrm{~nm}$. Chromatogram recordings and all calculations were performed on a Model C-R3A integrator (Shimadzu, Japan). The mobile phase consisted of ammonium acetate-acetic acid-methanol mixture. The composition of solvent $A$ was methanol: water $(4: 1, v / v)$ and solvent $\mathrm{B}$ was prepared as follows: $154 \mathrm{~g}$ ammonium acetate, $122 \mathrm{ml}$ water and $378 \mathrm{ml}$ acetic acid were mixed and $200 \mathrm{ml}$ of the resulting solution was added to $800 \mathrm{ml}$ of solvent $\mathrm{B}$ [8]. The flow rate was $0.8 \mathrm{ml} / \mathrm{min}$. The OPA derivatization reagent 